\title{
Administrative data based patient safety research: a critical review
}

\author{
C Zhan, M R Miller
}

Qual Saf Health Care 2003;12(Suppl II):ii58-ii63

Administrative data are readily available, inexpensive, computer readable, and cover large populations. Despite coding irregularities and limited clinical details, administrative data supplemented by tools such as the Agency for Healthcare Research and Quality (AHRQ) patient safety indicators (PSIs) could serve as a screen for potential patient safety problems that merit further investigation, offer valuable insights into adverse impacts and risks of medical errors and, to some extent, provide benchmarks for tracking progress in patient safety efforts at local, state, or national levels.

See end of article for authors' affiliations

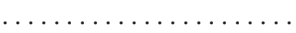

Correspondence to: Dr C Zhan, Center for Quality Improvement and Patient Safety, Agency for Healthcare Research and Quality, 540 Gaither

Road, Rockville, MD

20852, USA;

czhan@ahrq.gov
$\mathrm{T}$ he first and most critical obstacle in the patient safety campaign is the lack of a system that can reliably identify and report medical errors. ${ }^{1}$ Such a system is a prerequisite to study the magnitude of the problem, to identify risks and correlated factors, to find solutions, and to examine the effectiveness of any intervention aimed at reducing medical errors.

Medical records have so far been the primary source for researching medical errors. Over $90 \%$ of the original studies reviewed by the 1999 Institute of Medicine (IOM) report involve medical record abstractions. ${ }^{1}$ This system contains rich clinical details that allow identification of various medical injuries and near misses and analysis of circumstances and causes of errors. A significant limitation of this system is that medical records are mostly in paper format or electronic format that is not readily usable for research. Transforming medical records into research data is resource intensive and requires exceptional knowledge and skills in medical context and research. As a result, patient safety research with medical records is usually limited in scope and statistical power. Alternative systems for safety research include mandatory and voluntary reports of medical errors, drug safety surveillance, nosocomial infection surveillance, and medical malpractice data. All of these systems have limitations and/or access difficulties. For example, about 20 US states mandate reporting serious adverse events such as unanticipated death, brain or spinal cord damage but no published study has ever used the data, probably because they are strictly guarded from the public and researchers. ${ }^{2}$

Administrative data are a viable source, and their potential in patient safety research is increasingly recognized. They are readily available, inexpensive, computer readable, typically continuous, and cover large populations. In the early 1970s administrative data were used to reveal startling small area variations in health care and practice patterns. ${ }^{3}$ In the 1980s many researchers started using the data for outcomes research. ${ }^{4}$ Since the early 1990s researchers have been exploring the potential of administrative data in assessing quality and patient safety. Notable examples are the complication screening programs (CSP) by Iezzoni and colleagues ${ }^{5}$ and the Agency for Healthcare Research and Quality (AHRQ)'s quality indicators. ${ }^{6}$ In 2002 AHRQ developed and released the patient safety indicators (PSIs), ${ }^{7}$ a tool specifically designed for screening administrative data for patient safety events and medical errors. This development opened a new stage and opportunities for patient safety research using administrative data.

This paper provides a critical review of the progress in administrative data based patient safety research, with a focus on the PSIs and initial analysis of applying the PSIs to hospital discharges in a sample of general hospitals in the US. The merits and limitations of claims based systems are reviewed and the potential applications and future challenges discussed.

\section{ADMINISTRATIVE DATA BASED PATIENT SAFETY RESEARCH}

We conducted an extensive literature review aimed at identifying all empirical research in patient safety or medical errors that used administrative data. Our review started with the IOM report, ${ }^{1}$ the review performed by the University of California at San FranciscoStanford Evidence-Based Practice Center under contract with $\mathrm{AHRQ},{ }^{8}$ Iezzoni's review of administrative data based research on quality of care,? and our previous research. ${ }^{1011}$ We then carried out a systematic search of Medline and AHRQ grant databases from 1966 to 2002 using the following search algorithm ((patient safety OR medical error* OR medical-errors* OR adverse event* OR complication* OR iatrogenic* OR nosocomial) AND (administrative data* OR insurance-claim-review* ${ }^{*}$ OR claims data or ICD-9-CM)).

\section{Use of administrative data in quality and safety assessment}

Administrative data, also called claims data, are by-products of administering and reimbursing healthcare services. Government payers (such as Medicare, Medicaid and Veterans Affairs) and private insurance companies regularly maintain a large amount of administrative data concentrated primarily on acute hospital admissions and, increasingly, on outpatient care, nursing homes, home care, and hospice programs. The core data elements of an administrative data system are admission date, discharge date and 
status, primary and varying numbers of secondary International Classification of Diseases, 9th Revision, Clinical Modification (ICD-9-CM) diagnoses, procedures, and external causes of injury, and some demographic variables. These data are often available as compiled research databases from federal agencies, state health departments, health plans, and private data institutions. For example, AHRQ Healthcare Cost and Utilization Project (HCUP), a partnership of federal government and over 30 participating states, compiles uniform hospital discharge records for research purposes (see http://www.ahrq.gov/data/hcup/ for more details).

Overall, there has been limited use of administrative data in quality and safety research. Roos and Brazauskas in 1990 ${ }^{12}$ proposed screening claims data for adverse events and to guide subsequent medical record reviews to determine whether a quality problem existed. Leatherman et al in $1991^{13}$ described a quality screening and management program developed at the United Healthcare Corporation that used claims data to explore incidence rates, adverse events, and other outcomes measures. Riley et al in $1993^{14}$ used ICD-9-CM codes in Medicare claims to identify readmission to hospital for adverse events following selected procedures.

The work of Iezzoni and colleagues on CSP in the early $1990 s^{5}{ }^{1516}$ supported by AHRQ, was the first systematic exploration of the value of administrative data in quality and patient safety research. The CSP relied on ICD-9-CM codes to identify 27 potentially preventable in-hospital complications such as postoperative pneumonia, hemorrhage, medication incidents, and wound infection. Iezzoni et $a l^{16}$ found that patients with complications were significantly older, more likely to have comorbid conditions, more likely to die, and were higher in charges and lengths of stay than other patients. They also found that hospital complication rates generally were correlated across clinical areas, but not correlated with hospital mortality rates. ${ }^{15}$ Higher relative rates of complications were associated with larger hospitals, availability of major teaching facilities, and provision of open heart surgery, as well as with coding more diagnoses per case. ${ }^{15}$ Such findings, along with findings from other studies, ${ }^{5}{ }^{17-19}$ suggested that the CSP had certain clinical validity for research use, but also cast some doubts on the usefulness of CSP as a tool for provider level quality assessment.

In the mid 1990s AHRQ developed a set of administrative data based quality indicators as a companion tool for HCUP, named HCUP QIs. ${ }^{6}$ The 33 original QIs included several measures of avoidable adverse events and complications. Given the substantial nationwide interest in quality of care and a lack of quality assessment tools, the QIs were soon found in empirical studies. For example, Needleman and colleagues $^{20}$ at Harvard University and Kovner and colleagues $^{21}$ at AHRQ used some of these QIs to assess the association between inadequate nurse staffing and high rates of complications in hospitalized patients.

The IOM's call to develop medical error reporting systems three years ago $^{1}$ prompted renewed interest and vigor in developing a tool specifically designed for patient safety research that takes advantage of the large volume of existing claims data. Researchers at $\mathrm{AHRQ}^{10}$ compiled a list of potential administrative data measures from CSP, HCUP QI and other published works, and from hand searching ICD-9CM codes for complications, adverse events, medical negligence, and iatrogenic conditions. For each potential indicator, ICD-9-CM code inclusion and exclusion criteria were created to identify appropriate risk pools and to minimize ambiguity as to whether an event was a true error or an unpreventable complication. This list of potential codes was grouped into 13 measures based on clinical cohesiveness of the codes. Analyses using this algorithm revealed significant safety incidences and associated adverse patient outcomes in both hospitalized adults ${ }^{10}$ and children. ${ }^{11}$

Realizing the potential value of administrative data based measures to screen for patient safety events, AHRQ contracted with the Evidence-Based Practice Center (EPC) at the University of California San Francisco (UCSF) and Stanford University to further expand, test, and refine these measures as well as to improve the evidence behind their use with extensive literature reviews and broad clinical consensus panels. The final product of this joint effort is the AHRQ patient safety indicators (PSIs).

\section{AHRQ PATIENT SAFETY INDICATORS (PSIS)}

The UCSF-Stanford team developed AHRQ PSIs by a five step process $^{822}$ :

- they reviewed the literature to develop a list of candidate indicators in addition to the initial PSIs developed at AHRQ and collected information about their performance;

- they formed several panels of clinician experts to solicit their judgment of clinical sensibility and suggest revisions to the candidate indicators;

- they consulted ICD-9-CM coding experts to ensure that the definition of each indicator reflected the intended clinical situation;

- they conducted empirical analysis of the promising indicators using HCUP data; and

- they produced the software and documentation for public release at AHRQ.

The PSIs include 20 indicators with reasonable face and construct validity, specificity, and potential for fostering quality improvement. Seven of the PSIs are recommended to be area based PSIs to capture complications/adverse events occurring in an area as opposed to within an institution. The PSI software calculates raw rates, risk adjusted rates derived by applying the average case mix of a baseline file that reflects a large proportion of the US hospitalized population in patient age, sex, diagnosis related groups (DRGs) and comorbidities, and smoothed rates that dampen random fluctuations over time. ${ }^{7}$ Thirty co-morbidity categories ${ }^{23}$ are automatically generated by the software and used as risk adjusters together with variables available in most administrative data systems. Table 1 describes the definitions of the numerators, denominators, and key exclusions for the 20 PSIs, and table 2 provides the findings from applying the PSI to the 7.45 million discharges in the HCUP Nationwide Inpatient Sample for the year 2000. Note that each PSI has a unique risk pool determined by its denominator definition and exclusion criteria. Table 3 presents unadjusted length of stay, charges, and in-hospital mortality for patients with and without PSI events. Tables 2 and 3 show substantial numbers of patient safety events with tangible impacts on patient outcomes in terms of increased length of stay, increased likelihood of in-hospital death, and increased charges for patients experiencing a PSI event as opposed to those that do not. Taken together, these tables clearly point to a significant potential role for administrative data in patient safety efforts.

\section{CHALLENGES OF ADMINISTRATIVE DATA BASED PATIENT SAFETY RESEARCH}

Any discussion of patient safety research using administrative data should recognize some data limitations and understand how such limitations play in their analysis. In particular, we focus on how these issues relate to the PSI and/ or are addressed by the PSI. 
Table 1 Definitions of AHRQ patient safety indicators

\begin{tabular}{|c|c|c|c|}
\hline Patient safety indicator & Numerator definition & Denominator definition & Key exclusions \\
\hline $\begin{array}{l}\text { Anesthesia reactions and } \\
\text { complications }\end{array}$ & $\begin{array}{l}\text { Adverse effects of or poisoning } \\
\text { by anesthetic, endotracheal } \\
\text { tube wrongly placed }\end{array}$ & All surgical discharges & $\begin{array}{l}\text { Poisoning due to drug dependence or abuse, } \\
\text { self-inflicted injury }\end{array}$ \\
\hline Death in low mortality DRGs & In-hospital death & $\begin{array}{l}\text { DRGs with less than } 0.5 \% \text { mortality } \\
\text { in } 1997 \text { NIS }\end{array}$ & Trauma, cancer, immune compromise \\
\hline Decubitus ulcer & Pressure ulcer & $\begin{array}{l}\text { All medical and surgical discharges } \\
\text { with }>4 \text { day stay }\end{array}$ & $\begin{array}{l}\text { MDC 9, admission from long term care, } \\
\text { paralysis }\end{array}$ \\
\hline Failure to rescue & In-hospital death & $\begin{array}{l}\text { Acute renal failure, deep vein } \\
\text { thrombosis, pulmonary embolus, } \\
\text { pneumonia (including aspiration), } \\
\text { shock, cardiac arrest, gastrointestinal } \\
\text { hemorrhage/acute ulcer }\end{array}$ & $\begin{array}{l}\text { Transfer to or from acute care hospital, } \\
\text { admission from long term care, principal } \\
\text { diagnosis related to the denominator } \\
\text { condition }\end{array}$ \\
\hline $\begin{array}{l}\text { Foreign body left during } \\
\text { procedure }\end{array}$ & $\begin{array}{l}\text { Foreign body accidentally left } \\
\text { during procedure }\end{array}$ & All medical and surgical discharges & None \\
\hline latrogenic pneumothorax & latrogenic pneumothorax & All medical and surgical discharges & $\begin{array}{l}\text { Trauma, cardiothoracic surgery, lung or } \\
\text { pleural biopsy }\end{array}$ \\
\hline $\begin{array}{l}\text { Infection due to medical } \\
\text { care }\end{array}$ & $\begin{array}{l}\text { Infection following infusion, } \\
\text { injection, or transfusion, or } \\
\text { due to vascular device or graft }\end{array}$ & All medical and surgical discharges & Cancer, immune compromise \\
\hline Postoperative hip fracture & Postoperative hip fracture & All surgical discharges & $\begin{array}{l}\text { MDC 8, self-inflicted injury, cancers possibly } \\
\text { metastatic to bone, children, principal } \\
\text { diagnosis that could cause syncope or falls }\end{array}$ \\
\hline $\begin{array}{l}\text { Postoperative hemorrhage/ } \\
\text { hematoma }\end{array}$ & $\begin{array}{l}\text { Postoperative hemorrhage/ } \\
\text { hematoma with surgical } \\
\text { drainage or evacuation }\end{array}$ & All surgical discharges & Obstetric discharges \\
\hline $\begin{array}{l}\text { Postoperative physiological } \\
\text { or metabolic derangement }\end{array}$ & $\begin{array}{l}\text { Postoperative acute renal failure } \\
\text { requiring dialysis or diabetic } \\
\text { ketoacidosis, hyperosmolarity, } \\
\text { or hypoglycaemic coma }\end{array}$ & All elective surgical discharges & $\begin{array}{l}\text { Obstetric discharges, principal diagnosis } \\
\text { causally related to the numerator condition }\end{array}$ \\
\hline $\begin{array}{l}\text { Postoperative respiratory } \\
\text { failure }\end{array}$ & $\begin{array}{l}\text { Postoperative acute or acute on } \\
\text { chronic respiratory failure }\end{array}$ & All elective surgical discharges & MDC 4, MDC 5, obstetric discharges \\
\hline $\begin{array}{l}\text { Postoperative } \\
\text { thromboembolism }\end{array}$ & $\begin{array}{l}\text { Postoperative deep vein } \\
\text { thrombosis or pulmonary } \\
\text { embolus }\end{array}$ & All surgical discharges & $\begin{array}{l}\text { Obstetric discharges, principal diagnosis of } \\
\text { deep vein thrombosis }\end{array}$ \\
\hline Postoperative septicemia & Postoperative septicemia & $\begin{array}{l}\text { All elective surgical discharges } \\
\text { with }>3 \text { day stay }\end{array}$ & $\begin{array}{l}\text { Cancer, infection, immune compromise, } \\
\text { obstetric discharges }\end{array}$ \\
\hline $\begin{array}{l}\text { Postoperative abdominopelvic } \\
\text { wound dehiscence }\end{array}$ & $\begin{array}{l}\text { Secondary procedure to close } \\
\text { postoperative disruption of } \\
\text { abdominal wall }\end{array}$ & $\begin{array}{l}\text { All abdominopelvic surgical } \\
\text { discharges }\end{array}$ & Obstetric discharges \\
\hline $\begin{array}{l}\text { Accidental puncture or } \\
\text { laceration }\end{array}$ & $\begin{array}{l}\text { Accidental puncture or laceration } \\
\text { during procedure }\end{array}$ & All medical and surgical discharges & Obstetric discharges \\
\hline Transfusion reaction & $\mathrm{ABO}$ or $\mathrm{Rh}$ transfusion reaction & All medical and surgical discharges & None \\
\hline Birth trauma & $\begin{array}{l}\text { Intracranial hemorrhage, } \\
\text { extraclavicular fracture, spinal } \\
\text { injury, nerve injury (other than } \\
\text { facial and brachial plexus), other } \\
\text { birth trauma }\end{array}$ & All live births & $\begin{array}{l}\text { Preterm infants (for intracranial hemorrhage), } \\
\text { osteogenesis imperfecta (for fracture) }\end{array}$ \\
\hline $\begin{array}{l}\text { Obstetric trauma (vaginal } \\
\text { with instrumentation) }\end{array}$ & $\begin{array}{l}\text { Principal or secondary diagnosis } \\
\text { of fourth degree perineal, high } \\
\text { vaginal, or cervical laceration; } \\
\text { or procedure to repair any of } \\
\text { these lacerations }\end{array}$ & $\begin{array}{l}\text { All vaginal deliveries with forceps } \\
\text { or vacuum }\end{array}$ & None \\
\hline $\begin{array}{l}\text { Obstetric trauma (vaginal } \\
\text { without instrumentation) }\end{array}$ & Same & $\begin{array}{l}\text { All vaginal deliveries without forceps } \\
\text { or vacuum }\end{array}$ & None \\
\hline Obstetric trauma (caesarean) & $\begin{array}{l}\text { Same + uterine or urinary tract } \\
\text { laceration; or procedure to repair } \\
\text { any of these lacerations }\end{array}$ & All cesarean deliveries & None \\
\hline
\end{tabular}

All diagnosis based numerator definitions are based on secondary diagnoses unless otherwise noted.

$\mathrm{DRG}=$ diagnosis related group; $M D C=$ major diagnostic category.

\section{Problems with ICD-9-CM coding}

There are many concerns over ICD-9-CM coding with regard to patient safety research. First, we can only find events for which there are corresponding ICD-9-CM codes. A small number of standard codes and E codes appear to identify medical errors. For example, ICD-9-CM codes 9984, 9987, and E8710-E8719 can be used to record a foreign body left after a procedure. A coder should in theory code both the standard ICD-9-CM code and the E code. These codes, including $\mathrm{E}$ codes that are specifically designed to record injuries, in no way capture any significant percentage of the entire universe of medical errors that can occur. Secondly, there may be a substantial amount of coding errors due to misunderstanding of codes, or errors by physicians and coders, or miscommunications between them. An IOM study in 1977 found that agreement on the principal diagnosis between hospital reports and IOM reabstraction was only $65.2 \%{ }^{24}$ Thirdly, coding is very likely to be incomplete because of limited slots for coding secondary diagnoses and other reasons. Fourthly, assignment of ICD-9-CM codes is variable because of the absence of precise clinical definitions and context. Iezzoni and colleagues ${ }^{9}$ found that the mean number of diagnoses coded in 441 California hospitals ranged from 2.5 to 11.7 , and this variation explained part of the differences between high and low mortality hospitals. Some of the variation may be driven by financial reasons, such as in "DRG creep" where hospitals choose codes with higher Medicare pay schedules. ${ }^{25-27}$ Finally, diagnoses are not dated in current administrative data systems, making it difficult to determine whether a secondary diagnosis occurred before 
Table 2 Rates of patient safety events per 1000 discharges (HCUP Nationwide Inpatient Sample, 2000), $N=7448149$

\begin{tabular}{lccc}
\hline Patient safety indicators & $\begin{array}{c}\text { No of patient } \\
\text { safety events }\end{array}$ & Risk pool & $\begin{array}{c}\text { Event rate per 1000 } \\
\text { discharges at risk }\end{array}$ \\
\hline Complications of anesthesia & 1369 & 1933085 & 0.71 \\
Death in low mortality DRGs & 1169 & 2797528 & 0.42 \\
Decubitus ulcer & 41440 & 1932676 & 21.51 \\
Failure to rescue & 56103 & 331738 & 169.13 \\
Foreign body left in during procedure & 536 & 6572845 & 0.09 \\
latrogenic pneumothorax & 3919 & 5861689 & 0.67 \\
Infection due to medical care & 11449 & 5752102 & 1.99 \\
Postoperative hip fracture & 1068 & 1397898 & 0.77 \\
Postoperative hemorrhage or hematoma & 3494 & 1695495 & 2.06 \\
Postoperative physiological and metabolic & 799 & 801702 & 1.00 \\
derangements & & & \\
Postoperative respiratory failure & 2275 & 633855 & 3.58 \\
Postoperative thromboembolism & 15704 & 1689662 & 9.34 \\
Postoperative septicemia & 2592 & 229853 & 11.25 \\
Accidental puncture or laceration & 11810 & 5628112 & 3.32 \\
Transfusion reaction & 30 & 6572845 & 0.004 \\
Postoperative wound dehiscence & 843 & 411099 & 2.05 \\
Birth trauma - injury to neonate & 4740 & 720021 & 6.53 \\
Obstetric trauma (vaginal with instrument) & 12518 & 51225 & 224.21 \\
Obstetric trauma (vaginal without instrument) & 51223 & 591752 & 86.61 \\
Obstetric trauma (cesarean section) & 1138 & 191227 & 6.97 \\
\hline & & & \\
\hline
\end{tabular}

admission (a co-morbid disease) or during the stay in hospital (a complication or medical error). ${ }^{9}{ }^{18} 28$ Overall, these limitations were not amenable to be proactively addressed in developing the PSIs.

\section{Inadequate reliability and validity in identifying medical errors}

Administrative data have been shown to have low sensitivity but fair specificity in identifying quality gaps. Bates and colleagues $^{29}$ found that, while medical record review results in many false positives, administrative data were able to identify only half of patients with adverse events but had a fair specificity of $74 \%$. Iezzoni and colleagues conducted several validity studies on CSP. One study ${ }^{30}$ reported that physician reviewers confirmed CSP flagged complications in $68.4 \%$ of surgical and $27.2 \%$ of medical cases. Another study ${ }^{18}$ found that $89 \%$ of surgical cases and $84 \%$ of medical cases had their CSP trigger codes corroborated by review of the medical records. A third one ${ }^{19}$ indicates that objective clinical criteria or physicians' notes supported the coded diagnosis in $70 \%$ to over $90 \%$ of most CSP flagged conditions. Focusing on specific adverse events for a specific patient population, as is built into the PSIs, improves specificity appreciably. Romano et $a^{31}$ showed that specificity for postoperative complications after diskectomy can be as high as $98 \%$. No attempts have been made to identify the validity and reliability of AHRQ PSIs.

\section{Lack of clinical details for risk analysis and risk adjustment}

Lack of clinical details is a major limitation of claims data. ${ }^{32}$ Of special concern is severity of illness that affects patient outcomes and conceivably affects the likelihood of medical errors. Analysis of outcomes and risk factors associated with medical errors are limited to variables available from administrative data.

AHRQ PSIs and other similar tools usually identify a relatively homogeneous risk pool for each PSI which not only reduces misclassification but also alleviates variation in risk factors. ${ }^{56}$ Coding co-morbidities using ICD-9-CM codes represents another major effort built into the PSI for risk adjustment. ${ }^{23} 33-36$ Iezzoni $^{37}$ provided an excellent review of several claims based systems measuring severity. The performance of these systems depends substantially on complete coding of diagnoses. ${ }^{38}$

\section{Analytical issues}

The large size of the administrative data and the relative rarity of safety events requires special consideration in statistical analysis. The sheer size of the administrative data can give the illusion of great precision and power. ${ }^{39}$ Given the standard errors for cases with obstetric trauma without instrumentation and their risk pool (table 3), as an example, a difference of 0.014 days in length of stay in hospital between the two groups is statistically significant $(p<0.05)$. Such differences are often of little clinical significance. Coupled with missing important confounding variables and difficulty in choosing correct statistical models that fit the data, clinically insignificant but statistically significant results could lead to biased inferences and erroneous conclusions.

Matched case-control analysis appears to be a method particularly applicable to administrative data based analysis where cases are rare and controls are plenty. Classen et al $l^{40}$ and Bates et al ${ }^{41}$ matched cases of adverse drug reactions (ADR) with controls without ADR on DRG, co-morbidity, severity, and demographic characteristics to estimate the excess costs, mortality, and length of stay attributable to ADR. Jensen et $a^{42}$ matched cases of hospital acquired Staphylococcus aureus infections in Denmark hospitals to patients with the same primary diagnosis at admission to identify risk factors among unmatched factors such as age, anemia, etc. Bates et $a l^{43}$ matched patients with ADR with patients from the same hospital unit and similar pre-event length of stay to study risk factors for ADR. Matching retains only cases and controls with similar covariates. By matching cases and controls to the same hospitals, researchers could focus on patient level factors without concerns over hospital coding practices and hospital effects.

\section{POTENTIAL APPLICATIONS OF ADMINISTRATIVE DATA IN PATIENT SAFETY RESEARCH Patient safety indicators as a screening tool}

First and foremost, PSIs are considered indicators, not definitive measures, of patient safety concerns. ${ }^{10}{ }^{22}$ As with the $\mathrm{CSP}^{17}$ the intention of these indicators is to provide a 
Table 3 Means (SE) length of stay (LOS), charges, and mortality rates for discharges experiencing a patient safety indicator (PSI) event compared with those not experiencing a PSI event (unadjusted)

\begin{tabular}{|c|c|c|c|c|c|c|}
\hline Medical error & $\begin{array}{l}\text { LOS with } \\
\text { PSI event }\end{array}$ & $\begin{array}{l}\text { LOS without } \\
\text { PSI event }\end{array}$ & $\begin{array}{l}\text { Charge with } \\
\text { PSI event }\end{array}$ & $\begin{array}{l}\text { Charge without } \\
\text { PSI event }\end{array}$ & $\begin{array}{l}\text { Mortality (\%) } \\
\text { with PSI event }\end{array}$ & $\begin{array}{l}\text { Mortality (\%) } \\
\text { without PSI event }\end{array}$ \\
\hline Complications of anesthesia & $50.40(0.17)$ & $50.51(0.006)$ & $24572(838)$ & $25093(29)$ & $10.10(0.28)$ & $10.83(0.01)$ \\
\hline Death in low mortality DRGs & NA & NA & NA & NA & NA & NA \\
\hline Decubitus ulcer & $160.32(0.09)$ & $90.79(0.006)$ & 45987 (375) & $28100(29)$ & $130.85(0.17)$ & $40.01(0.01)$ \\
\hline Failure to rescue & $110.24(0.06)$ & $100.20(0.02)$ & $52879(364)$ & $34468(111)$ & NA & NA \\
\hline Foreign body left in during procedure & $90.30(0.75)$ & $40.78(0.002)$ & $41882(2938)$ & $14882(12)$ & $40.09(0.008)$ & $20.63(0.00)$ \\
\hline latrogenic pneumothorax & $130.78(0.25)$ & $40.59(0.003)$ & $55286(1454)$ & $13384(11)$ & $160.11(0.59)$ & $20.56(0.006)$ \\
\hline Infection due to medical care & $200.75(0.22)$ & $40.54(0.003)$ & 84751 (1096) & 13975 (12) & $100.31(0.003)$ & $20.11(0.0006)$ \\
\hline Postoperative hip fracture & $160.37(0.58)$ & $50.39(0.007)$ & $52224(1784)$ & $24594(35)$ & $90.93(0.92)$ & $10.70(0.01)$ \\
\hline Postoperative hemorrhage or hematoma & $110.74(0.27)$ & $50.77(0.006)$ & $57040(1334)$ & $27200(33)$ & $60.27(0.41)$ & $20.07(0.01)$ \\
\hline $\begin{array}{l}\text { Postoperative physiologic and metabolic } \\
\text { derangements }\end{array}$ & $210.35(0.78)$ & $40.13(0.006)$ & $114487(4261)$ & 20528 (33) & $280.16(10.59)$ & $0.75(0.01)$ \\
\hline Postoperative respiratory failure & $220.39(0.47)$ & $30.75(0.006)$ & $110397(2554)$ & $16602(22)$ & $290.39(0.96)$ & $0.39(0.007)$ \\
\hline Postoperative thromboembolism & $160.03(0.14)$ & $50.66(0.006)$ & $66805(736)$ & 26777 (32) & $310.56(0.25)$ & $130.94(0.01)$ \\
\hline Postoperative septicaemia & $250.10(0.48)$ & $70.20(0.01)$ & $113708(2486)$ & $32328(72)$ & $240.87(0.85)$ & $10.12(0.02)$ \\
\hline Accidental puncture or laceration & $80.34(0.08)$ & $60.92(0.003)$ & 38788 (427) & $16212(13)$ & $40.77(0.16)$ & $30.06(0.007)$ \\
\hline Transfusion reaction & $130.40(20.20)$ & $40.78(0.003)$ & 68372 (20193) & $14884(12)$ & $60.67(40.64)$ & $20.63(0.006)$ \\
\hline Postoperative wound dehiscence & $220.32(0.61)$ & $60.72(0.014)$ & $93022(3336)$ & $26623(75)$ & $330.66(10.16)$ & $160.53(0.026)$ \\
\hline Birth trauma - injury to neonate & $30.38(0.10)$ & $30.03(0.008)$ & $5111(372)$ & 4226 (33) & $0.65(0.12)$ & $0.33(0.007)$ \\
\hline Obstetric trauma (vaginal with instrument) & $20.42(0.016)$ & $20.28(0.008)$ & $5664(92)$ & $5976(115)$ & $0.016(0.011)$ & $0.003(0.003)$ \\
\hline Obstetric trauma (vaginal without instrument) & $20.17(0.005)$ & $20.09(0.002)$ & $5110(43)$ & $5206(23)$ & $0.002(0.002)$ & $0.003(0.001)$ \\
\hline Obstetric trauma (cesarean section) & $40.56(0.13)$ & $30.76(0.007)$ & $12614(496)$ & $9461(36)$ & $0(0)$ & $0.02(10.47)$ \\
\hline
\end{tabular}

useful screening tool to highlight areas in which quality should be investigated in greater depth. PSIs enable institutions to quickly and easily identify a manageable number of medical records for closer scrutiny. Using administrative data to screen cases for chart review has also been proposed by Roos and Brazauskas in 1990 and by Silber and colleagues more recently. ${ }^{12}{ }^{44}$ For example, in cases with a foreign body left in after surgery (table 2), 7.45 million medical records have to be extracted to uncover 536 cases. Screening the claims with PSIs would quickly identify such rare events and associated medical records could be abstracted for in-depth analysis. This approach has great potential in enhancing the design of medical record based patient safety research, but its use has yet to be widely adopted.

\section{Epidemiological study in patient safety}

Administrative data are valuable in epidemiological studies of the incidence and consequences and factors associated with medical injuries. Our earlier studies ${ }^{10}{ }^{11}$ and those of Romano et al $^{22}$ revealed substantial incidence rates and provided some insights into the outcomes and risk factors associated with medical errors. Our ongoing analysis of the 2000 data suggests that medical errors identified in table 2, excluding death in low mortality DRGs and failure to rescue where patients with errors all died during hospitalization, account for a total of 2.4 million extra days in hospital, \$9263 million extra charges, and 32591 attributable deaths in the US per year. It is also possible to identify certain risk factors such as nurse staffing..$^{20}$

\section{Public reporting}

At a time when no reliable reporting system exists, applying PSIs to administrative data could reveal the overall incidences and trends and provide useful benchmarks at the local, state, regional, and national levels for tracking progress. However, such use must be made with care. Coding differences across institutions, ${ }^{9}$ lack of robust risk adjustment, ${ }^{3745}$ relative rarity of safety events, and many other reasons make it uncertain that differences between PSI rates reflect true differences in quality. ${ }^{4631}$ Because of these limitations, public reporting of PSI rates for institutions and regions may raise contentions over technicalities rather than facilitate quality improvement. Developers of PSIs and similar administrative data based systems in general express caution with regard to the use of the indicators for public reporting at an institutional level. ${ }^{10} 22$

\section{CONCLUSION}

We have highlighted generic and specific concerns regarding administrative data and their use, in particular, for patient safety research. Despite the known limitations, the lack of tools for patient safety today makes administrative data based tools like the AHRQ PSIs appealing. AHRQ PSIs could be useful to identify potential patient safety problems that merit further investigation. With proper methodology, administrative data can provide valuable insights into the incidences, adverse impacts, and risks of medical errors. In addition, PSI rates could serve as useful monitors at local, state and national levels and as benchmarks for tracking progress in patient safety. Further research will be needed to establish whether, and under what circumstances, these indicators are valid measures of safety related hospital performance for comparative purposes. Most paramount in this effort is work at explicitly examining cases flagged by PSIs using chart review. Some of this work is already ongoing.

Future growth in electronic health data will make tools like the PSI more useful. Ongoing refinement of ICD-9-CM and, eventually, ICD-10-CM should introduce more data elements and may allow clearer distinction of complications from conditions present at admission and increase the specificity of codes. Iezzoni ${ }^{17}$ predicted that the definition, content, and scope of administrative data would change dramatically in the near future, and inclusion of clinical information from both clinicians and patients in administrative data would make exciting new possibilities.

In 2001 the Department of Health and Human Services (HHS) of the AHRQ launched a $\$ 50$ million initiative aimed at improving patient safety, focusing primarily on medical error data or reporting systems. ${ }^{47}$ The fruition of this investment will hopefully evolve into real time, user friendly, nationwide error reporting systems. It is conceivable that any eventual reporting system would involve triangulation between current administrative data, chart review, and selfreports in order to maximize the amount of information available with respect to medical errors. At present, the value of administrative data-with its large scale, uniformity, and 


\section{Pointers for future research}

- Understanding the clinical sensitivity and specificity of the AHRQ PSIs.

- Understanding the interplay between administrative data and self-reports or chart abstraction for research on patient safety.

- Development of multifaceted error reporting systems which make maximal use of all data available

\section{Key messages}

- Administrative data are readily available, inexpensive, and cover large populations.

- Tools such as the AHRQ PSI are available to begin identifying, tracking, and improving healthcare processes in the interest of patient safety.

- Researchers need to understand the issues and limitations of administrative data as they relate to studying patient safety events.

regularity-should be fully harvested in our campaign against medical errors.

\section{ACKNOWLEDGEMENTS}

The authors of this article are responsible for its content, including any clinical or treatment recommendations. No statement in this article should be construed as an official position of the Agency for Healthcare Research and Quality or the US Department of Health and Human Services.

\section{Authors' affiliations}

C Zhan, Center for Quality Improvement and Patient Safety, Agency for Healthcare Research and Quality, Department of Health and Human Services, Rockville, MD, USA

M R Miller, Department of Pediatrics, Johns Hopkins University, Baltimore, MD, USA

Dr Miller completed the analysis presented here while serving as Acting Director of the Center for Quality Improvement and Patient Safety at the Agency for Healthcare Research and Quality of the US Department of Health and Human Services.

\section{REFERENCES}

1 Kohn LT, Corrigan JM, Donaldson M, et al. To err is human: building a safer health system. Washington, DC: Institute of Medicine, 1999.

2 Leape LL. Reporting of adverse events. N Engl J Med 2002;347:1633-8.

3 Wennberg J, Gittlesohn A. Small area variations in health care delivery. Science 1973;182:1102-8.

4 Mitchell J, Bubolz T, Paul J, et al. Using Medicare claims for outcomes research. Med Care 1994;32: JS38-JS51.

5 lezzoni LI, Foley SM, Heeren T, et al. A method for screening the quality of hospital care using administrative data: preliminary validation results. $Q R B$ Qual Rev Bull 1992;18:361-71.

6 Johantgen M, Elixhauser A, Bali JK, et al. Quality indicators using hospital discharge data: state and national applications. Jt Comm J Qual Improv 1998;24:88-105.

7 AHRQ. AHRQ quality indicators - patient safety indicators: soffware documentation. Rockville, MD: Agency for Healthcare Research and Quality, 2002.

8 University of California at San Francisco-Stanford University Evidence-Based Practice Center. Evidence report for measures of patient safety based on hospital administrative data-the patient safety indicators. Rockville, MD: Agency for Healthcare Research and Quality, 2002.

9 lezzoni LI. Data sources and implications: administrative Database. In: lezzoni LI, ed. Risk adjustment for measuring health outcomes, 2nd ed. Chicago: Health Administration Press, 1997:169-242.
10 Miller RM, Elixhauser A, Zhan C, et al. Patient safety indicators: using administrative data to identify potential patient safety concerns. Health Serv Res 2001;36(6(Part II)): 110-32.

11 Miller RM, Elixhauser A, Zhan C. Patient safety events during pediatric hospitalizations. Pediatrics 2003;111:1358-66.

12 Roos LL, Brazauskas R. Outcomes and quality assurance: facilitating the use of administrative data. Qual Assur Health Care 1990;2:77-88.

13 Leatherman S, Peterson E, Heinen L, et al. Quality screening and management using claims data in a managed care setting. QRB Quality Review Bulletin $1991 ; 17: 349-59$.

14 Riley G, Lubitz J, Gornick M, et al. Medicare beneficiaries: adverse outcomes after hospitalization for eight procedures. Med Care 1993;31:921-49.

15 lezzoni LI, Daley J, Heeren T, et al. Using administrative data to screen hospitals for high complication rates. Inquiry 1994;31:40-55.

16 lezzoni LI, Daley J, Heeren T, et al. Identifying complications of care using administrative data. Med Care 1994;32:700-15.

17 lezzoni LI. Assessing quality using administrative data. Ann Intern Med 1997: 127:666-74.

18 Lawthers AG, McCarthy EP, Davis RB. Identification of in-hospital complications from claims data: is it valid? Med Care 2000;38:785-95.

19 McCarthy E, lezzoni L, Davis R, et al. Does clinical evidence support ICD-9CM diagnosis coding of complications? Med Care 2000;38:868-76.

20 Needleman J, Burerhaus P, Mattke S, et al. Nurse staffing levels and quality of care in hospitals. N Engl J Med 2002;346:1715-22

21 Kovner C, Gergen PJ. Nurse staffing and post-surgical adverse events: an analysis of administrative data from a sample of US hospitals, 1990-1996. Health Serv Res 2002;37:611-29.

22 Romano PS, Geppert J, Davies S, et al. A national profile of patient safety in US hospitals based on administrative data. Health Affairs 2003;22:154-66.

23 Elixhauser A, Steiner C, Harris DR, et al. Comorbidity measures for use with administrative data. Med Care 1998;36:8-27.

24 Institute of Medicine. Reliability of hospital discharge abstracts. Washington, DC: National Academy of Sciences, 1977.

25 Simborg DW. Creep: a new hospital-acquired disease. N Engl J Med 1981;304:1602-4

26 ProPAC. Medicare and the American health care system, Report to Congress. Washington, DC: Prospective Payment Assessment Commission, 1996.

27 Hsia D, Krushat WM, Fagan AB, et al. Accuracy of diagnostic coding for Medicare patients under the Prospective Payment System. N Engl J Med 1988;318:352-5.

28 Romano PS, Chan BJ. Risk-adjusting acute myocardial infarction mortality: are APR-DRGs the right tool? Health Serv Res 2000;34:1469-89.

29 Bates DW, O'Neil AC, Petersen LA, et al. Evaluation of screening criteria for adverse events in medical patients. Med Care 1995;33:452-62.

30 Weingart S, lezzoni L, Davis R, et al. Use of administrative data to find substandard care: validation of the complications screening program. Med Care 2000;38:796-808.

31 Romano PS, Chan BK, Schembri M, et al. Can administrative data be used to compare postoperative complication rates across hospitals. Med Care 2002:40:856-67.

32 Feinstein AR. ICD, POR and DRG: Unsolved scientific problems in the nosology of clinical medicine. Arch Intern Med 1988;148:2269-74.

33 Deyo R, Cherkin D, Ciol M. Adapting a clinical cormobidity index for use with ICD-9-CM administrative databases. J Clin Epidemiol 1992;45:613-9.

34 Romano PS, Roos LL, Jollis JG. Adapting a clinical comorbidity index for use with the ICD-9-CM administrative data: differing perspectives. J Clin Epidemiol 1993;46:1075-9.

35 Romano PS, Roos LL, Jollis JG. Further evidence concerning the use of a clinical comorbidity index with ICD-9-CM administrative data. J Clin Epidemiol 1993;46:1085-90.

36 Ghali WA, Hall RE, Rosen AK, et al. Searching for an improved clinical comorbidity index for use with ICD-9-CM administrative data. J Clin Epidemiol 1996:49:273-8.

37 lezzoni LI. Risks and outcomes. In: lezzoni LI, ed. Risk adjustment for measuring health outcomes, 2nd ed. Chicago: Health Administration Press, 1997: 1-42.

38 Hughes J, lezzoni LI, Daley J, et al. How severity measures rate hospitalized patients. J Gen Intern Med 1996;11:303-11.

39 Mark DH. Race and the limit of administrative data. JAMA 2001;285:337-8.

40 Classen DC, Pestotnik SL, Evans RS, et al. Adverse drug events in hospitalized patients. Excess length of stay, extra costs, and attributable mortality. JAMA 1997;277:301-6.

41 Bates DW, Spell N, Cullen DJ, et al. The costs of adverse drug events in hospitalized patients. JAMA 1997;277:307-11.

42 Jensen AG, Wachmann GH, Poulsen KB, et al. Risk factors for hospitalacquired Staphylococcus aureus bacteremia. Arch Intern Med 1999; 159: 1437-44.

43 Bates DW, Miller EB, Cullen DJ, et al. Patient risk factors for adverse drug events in hospitalized patients. Arch Intern Med 1999;159:2553-60.

44 Silber $\mathrm{JH}$, Rosenbaum P, Trudeau ME, et al. Multivariate matching and bias reduction in the surgical outcomes study. Med Care 2001;39:1048-64.

45 DesHarnais S, McMahon U, Wroblewski R, et al. Measuring hospital performance: the development and validation of risk adjusted indexes of mortality, readmissions, and complications. Med Care 1990;28:1 127-41.

46 Hannan E, Kilburn HJ, Lindsey $M$, et al. Clinical versus administrative data bases for CABG surgery: does it matter? Med Care 1992;30:892-907.

47 AHRQ. HHS announces $\$ 50$ million investment to improve patient safety. Rockville, MD. Available at http://www.ahrq.gov/news/press/pr2001/ patsafpr.htm and http://www.ahrq.gov/qual/newgrants/index.html, 2001. 